\title{
Análise da temperatura aparente de superfície e Índice de Vegetação por Diferença Normalizada (NDVI) em Lisboa, Portugal, no verão de 2017
}

\section{Renan Valério Eduvirgem ${ }^{1}$, André Jesus Periçato ${ }^{1}$, César Costa Sanches ${ }^{1}$, Claudemir Rodrigues Soares ${ }^{1}$, Laine Milene Caraminan ${ }^{2}$, Matheus Vinicius dos Santos ${ }^{2}$}

${ }^{1}$ Programa de Pós-Graduação em Geografia. Universidade Estadual de Maringá. Maringá-PR. Brasil. (CEP 87020-900). E-mail: georenanvalerio@gmail.com.

${ }^{2}$ Departamento de Geografia. Universidade Estadual de Maringá. Maringá-PR. Brasil. (CEP 87020-900). E-mail: caraminanlaine@gmail.com.

Resumo. Os problemas ambientais urbanos estão relacionados aos processos históricos de ocupação e formação do espaço geográfico, bem como, às transformações que ocorrem ao longo dos anos tendo em vista às necessidades dos grupos sociais. A gestão ambiental surge então com o intuito de amenizar os problemas ambientais encontrados nos sitios urbanos, ao passo que, estes mantem relações diretas com a qualidade de vida da população. Nesse sentido, o presente trabalho busca monitorar a temperatura de superficie da cidade de Lisboa no verão do ano de 2017, através da técnica de sensoriamento remoto a partir da aplicação do Indice de Temperatura Aparente de Superfície (TAS) correlacionando com a distribuição espacial da cobertra vegetal através do Índice de Vegetação por Diferença Normalizada (NDVI). Os resultados mostram que a área urbana de Lisboa para o mês de julho de 2017 apresentou temperaturas mínimas variando de $21,50{ }^{\circ} \mathrm{C}$ e $29,00{ }^{\circ} \mathrm{C}$ e máximas de $36,24^{\circ} \mathrm{C}$ e $43,22^{\circ} \mathrm{C}$. Para o mês de agosto, as temperaturas mínimas e máximas foram de $23,47{ }^{\circ} \mathrm{C}$ e $41,72{ }^{\circ} \mathrm{C}$, respectivamente. O NDVI indicou as localidades que apresentam maior cobertura vegetal, com destaque para os Parques florestais da cidade. A TAS e o NDVI mostraram-se inversamente proporcionais, onde as maiores temperaturas foram localizadas nos locais que apresentam as menores constituições arbóreas. Ainda, percebe-se que as formações vegetais são um dos fatores responsáveis pelas diferenças de temperaturas encontradas na área, contribuindo diretamente para o microclima local.

Palavras-chave: Clima urbano; Imagem termal; Landsat8; Sensoriamento remoto.

Abstract. Analysis of apparent surface temperature and Normalized Difference Vegetation Index in Lisbon, Portugal, summer of 2017. The urban environmental problems are related to the historical processes of occupation and formation of the
Recebido:

03/07/2018

Aceito:

$20 / 08 / 2018$

Publicado:

$31 / 08 / 2018$

Acesso aberto

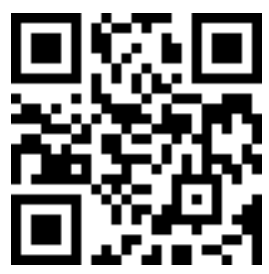

ORCID

(D) $0000-0002-9830-869 \mathrm{X}$ Renan Valério

Eduvirgem

(D) 0000-0002-3897-2820

André Jesus Periçato

(D) 0000-0003-4425-8807 César Costa Sanches

D 0000-0001-5985-7533

Claudemir Rodrigues

Soares

(D) 0000-0001-8239-2578

Laine Milene

Caraminan

D) 0000-0003-3031-7925

Matheus Vinicius dos

Santos 
geographic space, as well as the transformations that occur over the year in view of the need to the social groups. The environmental management arise then with the intention of relieve the environmental problems found in urban sites, in order that, this keep direct relation with the quality of life of the population. This way, the present work search to monitor the surface temperature in the city of Lisbon in the summer of 2017 through remote sensing technique and the application of the Apparent Surface Temperature Index (TAS) correlating with the special distribution of the vegetation cover using the Normalized Difference Vegetation Index (NDVI). The results show that the urban area of Lisbon for the month of July of 2017 presented minimum temperatures ranging from $21.50{ }^{\circ} \mathrm{C}$ and $29.00{ }^{\circ} \mathrm{C}$ and maximum of $36.24{ }^{\circ} \mathrm{C}$ and $43.22^{\circ} \mathrm{C}$. For the month of august, the minimum and maximum temperatures were $23.47^{\circ} \mathrm{C}$ and 41.72 ${ }^{\circ} \mathrm{C}$, respectively. The NDVI indicated the locations with the highest vegetation coverage, with emphasis on the city's forest park. The TAS and NDVI showed be inversely proportional, where the highest temperatures were located at sites with the lowest tree constitutions. Yet, it is noticed that the vegetal formations are one of the factors responsible for the temperature differences found in the area, contributing directly to the local microclimate.

Keywords: Urban climate; Thermal image; Landsat8; Remote sensing.

\section{Introdução}

A gestão ambiental compreendese como a gerência das relações entre o ambiente e os seres humanos (Costa et al., 2017). A relação entre pessoas e ambiente é fundamental para o desenvolvimento sustentável, principalmente no que concerne ao ambiente urbano, haja vista que a população aumenta em diferentes escalas concomitantemente a evolução urbana. Assim, a gestão ambiental é essencial para minimizar os impactos gerados pelos seres humanos.

Segundo os dados do IPMA (2017) em Portugal continental, o verão de 2017 (junho, julho, agosto) foi classificado como quente e extremamente seco, com temperatura média acima do normal e quantidade de precipitação inferior aos verões dos anos anteriores. Em Lisboa não foi diferente do detectado no país.

Este trabalho tem como objetivo promover uma contribuição por meio da análise de Temperatura Aparente de Superfície (TAS) de Lisboa, Portugal, demonstrando as localidades com maior temperatura, para que futuramente $o$ mesmo possa auxiliar na tomada de decisão da gestão do ambiente urbano na perspectiva sustentável.

O clima urbano é uma temática estudada por diversos autores, inclusive com a formulação de teorias com a teoria sistema clima urbano (SCU) (Monteiro, 1976; 2003), que trata da dinâmica climática no espaço geográfico.

Lombardo (1985) afirma que as mudanças na superfície terrestre são resultantes do adensamento e crescimento populacional, do acréscimo de construções urbanas de grande e médio porte à custa da redução vegetal natural e dos cursos d'água, que promovem mudanças significativas nas propriedades atmosféricas, alterando o balanço de calor em superfície, concomitantemente a redefinição do clima urbano. 
Quando as alterações atmosféricas são realizadas pelos seres humanos no âmbito urbano, é denominado de microclimas, nesse caso, microclima urbano ou das cidades.

As geotecnologias em conjunto com as técnicas de sensoriamento remoto, auxiliam nas análises do clima urbano, porque as imagens de satélites estão cada vez com melhores resoluções, fruto da evolução tecnológica dos satélites, assim, beneficiando os estudos de TAS. Estudos recentes de TAS foram realizados por Peng et al. (2011), Flores R. et al. (2016), Silva, Silva \& Santos (2018) e Amorim (2017; 2018).

Eduvirgem e Ferreira (2017) realizaram estudo sobre TAS, cujos autores identificaram localidades nas proximidades de um córrego com maior e menor temperatura, diante dos resultados obtidos os autores, recomendaram o plantio de espécies que compõem a Floresta Estacional Semidecidual, pelo fato que essa vegetação compõe essa região, e promovera o sombreamento de elementos artificiais, que emitem forte brilho. Assim, podemos observar que os autores recomendam plantio de cobertura vegetal para auxiliar na mitigação de temperatura aparente de superfície, além das cores e materiais que compõe a morfologia urbana.

Deng et al. (2018) enfatizaram em seus estudos a relação entre a TAS e o Índice de Vegetação da Diferença Normalizada (NDVI), na estação de verão, que apresentou resultados significativos com temperaturas elevadas, apresentando os pontos mais significativos para análise. Os autores também enfatizam a correção atmosférica. No estudo deste trabalho promovemos não somente a relação do NDVI com a TAS, mas também a correção atmosférica para otimizar os resultados obtidos com maior precisão.

Com alusão ao NDVI, Quesada et al. (2017) afirma que este índice é um dos mais importantes indicadores para a análise da cobertura de vegetação em diferentes períodos utilizando técnicas de sensoriamento remoto. Este índice tem o propósito de observar as mudanças na cobertura do solo causadas por atividades antrópicas, assim como seu desenvolvimento.

O NDVI pode ser obtido por meio do processamento de imagens de satélite, com base em diferentes refletâncias, na interação radiação e cobertura vegetal (FU \& BURGHER, 2015). De acordo com os autores citados pode-se entender que o NDVI tem papel importante como índice para mostrar a deterioração e condição da vegetação em absorver a radiação fotossintética. Este índice possibilita verificar a fase de desenvolvimento e densidade da planta numa determinada localidade da área de estudo, conforme a vegetação características.

A literatura apresenta muitos estudos que utilizam o NDVI para mensurar a densidade de cobertura vegetal com base na sensibilidade da vegetação primária e secundária que esta à margem dos cursos d'água, que define a variação espacial ao longo dos rios e lagos.

O NDVI além de mensurar as localidades com quantidades distintas de vegetação é utilizado também para investigar os impactos das diferentes condições climáticas. Zheng et al. (2018) empregaram o NDVI em seus estudos como um indicador para refletir a resposta da dinâmica da vegetação correlacionado com o clima, para verificação de impactos climáticos. Entretanto, deve-se ter cautela com as ações antrópicas, pois as mesmas também provem a degradação ambiental. Deste modo podemos observar que diferentes pesquisadores utilizam o NDVI para diferentes finalidades, como Whetton et al. (2017), cujos autores correlacionaram o NDVI com as propriedades do solo. 


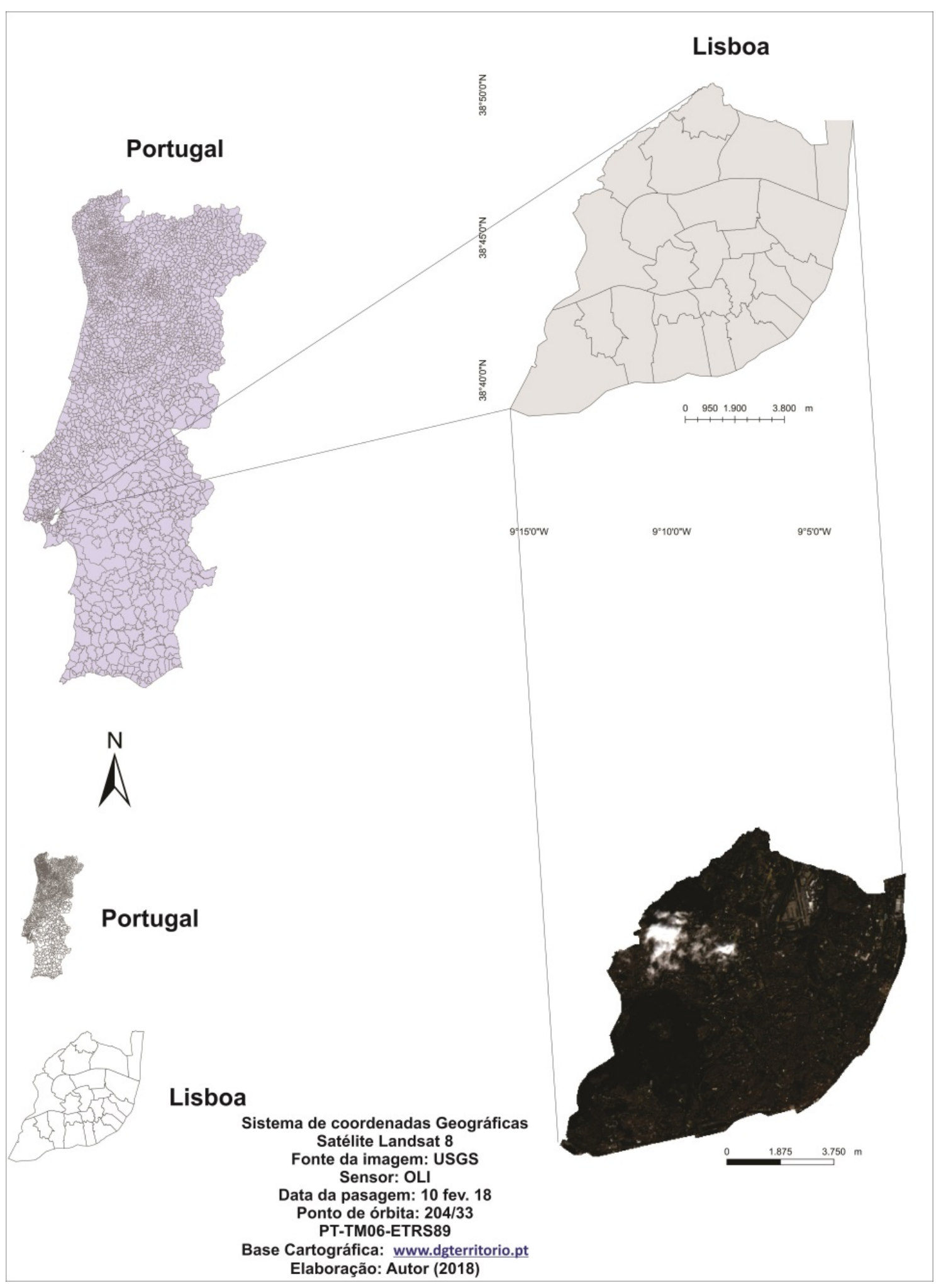

Figura 1. Mapa de localização de Lisboa. 


\section{Procedimentos metodológicos}

\section{Localização da área de estudo}

A área de estudo está no âmbito dos limites administrativos da cidade de Lisboa, com área de $83,84 \mathrm{~km}^{2}$ (Figura 1). A população é de cerca de 547.733 habitantes (INE, 2011), apesar da Área Metropolitana de Lisboa ultrapassar os 2 milhões de habitantes.

O clima é do tipo mediterrânico Csa, de acordo com a classificação de Köppen, com inverno chuvoso e verão quente e seco.

Segundo o Instituto Português do Mar e da Atmosfera (IPMA, 2018), as temperaturas médias variam entre $11,6^{\circ} \mathrm{C}$ em janeiro a $23,5^{\circ} \mathrm{C}$ em agosto (Normais Climatológicas 1981-2010). A precipitação anual média é de $726 \mathrm{~mm}$.

\section{Para a determinação da TAS}

Para atender os objetivos aplicados da pesquisa, foram adquiridas imagens da área de estudo no sítio da United States Geological Survey (USGS), correspondente ao período de $15 / 06 / 2017$ a 02/08/2018, correspondendo a três imagens termais que expressam as temperaturas do verão em 2017. Os dados de entrada foram das imagens do satélite Landsat 8, na banda 10 (infravermelho termal).

Para obter os valores de temperatura de superfície foi utilizado o software Esri ArcGis 10.2®.

Na determinação da temperatura de superfície foi utilizado o guia empregado pelo Center for Earth Observation, da Universidade de Yale, disponível em <https://surfaceheat.sites. yale.edu/understanding-landsat-8>. Este método possui embasamento na Lei de Planck, que faz alusão ao corpo negro. Trata-se de um corpo hipotético que pode absorver e emitir a radiação eletromagnética em todos os comprimentos de onda de forma isotrópica, que pode ser produzida como à quarta potência da temperatura de superfície do objeto (equação 1).
Energia emitida por um corpo negro $=6 t 4$

(eq. 1)

Em que: "6" constante de Stefan-Boltzmann $(5,67 \times 10-8 \mathrm{w} / \mathrm{m} 2 \mathrm{k} 4)$.

Todavia, como nenhuma superfície real se comporta como um corpo negro, deve-se considerar a seguinte fórmula (equação 2).

$$
\text { Energia real emitida }=\varepsilon 6 t 4 \quad \text { (eq. } 2 \text { ) }
$$

Em que: " $\varepsilon$ ": emissividade da superfície, que varia entre 0 e 1 .

Os elementos presentes na terra apresentam emissões que variam de 0,8 a 0,95 . Sendo alguns materiais como metais, sem revestimento, podem apresentar valores variando de 0,2 a 0,6. Para ser possível a obtenção dos valores de temperatura da superfície, utilizou-se as fórmulas, sendo a primeira responsável pela transformação dos valores ND (números digitais coletados via satélite), que vão de 0 (branco) a 255 (preto), em valores de radiância (equação 3).

$$
\mathrm{L} \lambda=\mathrm{MLQcal}+\mathrm{AL}
$$

Em que:

$\mathrm{L} \lambda=$ Radiância do topo da atmosfera (Watts $\left./\left(\mathrm{m}^{2} * \operatorname{srad}^{*} \mu \mathrm{m}\right)\right)$;

$\mathrm{ML}=$ Fator multiplicativo de redimensionamento de cada banda presente nos metadados (Radiance_Mult_Band_x, onde x é o número da banda);

$\mathrm{AL}=$ Fator aditivo de redimensionamento de cada banda presente nos metadados (Radiance_Add_Band_x, onde x é o número da banda);

Qcal $=$ Valores de pixel quantificados e calibrados do produto padrão (DN).

Aplicou-se a equação 4 para converter os valores em temperatura Kelvin, e subtraído o resultado por "273,15 " para converter para graus Celsius $\left({ }^{\circ} \mathrm{C}\right)$. 


$$
T=\frac{K_{2}}{\operatorname{In}\left(\frac{K 1}{L A}+1\right)}-273,15
$$

Em que:

$\mathrm{T}=$ Temperatura efetiva no satélite em Kelvin;

$\mathrm{K}_{2}=$ Constante de calibração 2 - valor - 1 321,08

$\mathrm{K}_{1}$ = Constante de calibração de 1 - valor 774,89

$\mathrm{L}$ = Radiância espectral, em Watts/(metro quadrado ster ** mm).

\section{Para a determinação do NDVI}

0 realce da vegetação pelo NDVI, leva em consideração, as relações entre a refletância do solo e da vegetação, sendo que a vegetação possui elevada refletância na região do Infravermelho Próximo, já o solo na região do vermelho. Assim, quanto maior for à densidade da cobertura vegetal, inferior será a refletância na região do visível vermelho, todavia, será superior a refletância na região do Infravermelho Próximo.

Para o cálculo de NDVI foi utilizado a seguinte equação:

$$
N D V I=(\rho N I R-\rho R E D) /(\rho N I R+\rho R E D) \text { (eq. } 5)
$$

Em que:

NDVI = Índice de Vegetação por Diferença Normalizada;

pNIR = reflectância na banda do infravermelho próximo;

pRED = é a reflectância na banda vermelha.

Os valores obtidos no NDVI variam entre +1 e -1 , em que, quanto mais próximo de -1 , menor a densidade da cobertura vegetal, e quanto mais próximo de +1 , maior é a densidade.

\section{Resultados e discussões}

A TAS deste estudo foi classificada em cinco classes. Para 15/06/2017 apresentou mínimas de $21,51{ }^{\circ} \mathrm{C} \quad$ a $28,86^{\circ} \mathrm{C}$ e máximas de $35,07^{\circ} \mathrm{C}$ a $40,83^{\circ} \mathrm{C}$. As temperaturas mínimas estão distribuídas de maneira heterogênea no espaço urbanizado de Lisboa, haja vista que a maior concentração está presente nas áreas a sudoeste, com maior presença de áreas verdes. As temperaturas acima de $34^{\circ} \mathrm{C}$ e inferiores a $40,83^{\circ} \mathrm{C}$ desmonstraram-se presentes na maior parte do território, com áreas com maior dimensão espacial ao norte. As temperaturas entre $28,86^{\circ} \mathrm{C}$ a $33,33^{\circ} \mathrm{C}$ foram identificadas na área central e nas proximidades a leste do verde urbano, como observa-se na região sudeste (Figura 2).

Com os dados de 17/07/2017 foi possível extrair os valores termais, que originou $21,50{ }^{\circ} \mathrm{C}$ de mínima e máxima de $43,22^{\circ} \mathrm{C}$. A amplitude aferida foi de $21,72^{\circ} \mathrm{C}$. Resultado semelhante foi encontrado por Morais (2011), que também encontrou TAS superiores aos $40^{\circ} \mathrm{C}$. Quanto à distribuição das temperaturas mais elevadas, a concentração ocorreu à oeste, noroeste e centro-norte de Lisboa. As temperaturas menores concentraram-se ao sul para esta data (Figura 2).

Para o mês de agosto de 2017 a temperatura mínima encontrada foi $23,47^{\circ} \mathrm{C}$ e a máxima $41,72{ }^{\circ} \mathrm{C}$. No mês referido a concentração das menores temperaturas perderam porporção espacial ao sul em relação ao mês de julho. A TAS entre $32,63{ }^{\circ} \mathrm{C}$ a $36,21^{\circ} \mathrm{C}$ predominaram em quase todo $\mathrm{o}$ território, com exceção das áreas a sudoeste que concentra o aglomerado de verde urbano com diferentes rugosidades (Figura 2).

$O$ verde urbano que expressou os menores valores de TAS é composto pelo Parque Recreativo do Alto da Serafina, Lisboa Camping \& Bungalows, Parque Urbano do Calhau e o Parque Florestal de Monsanto. 


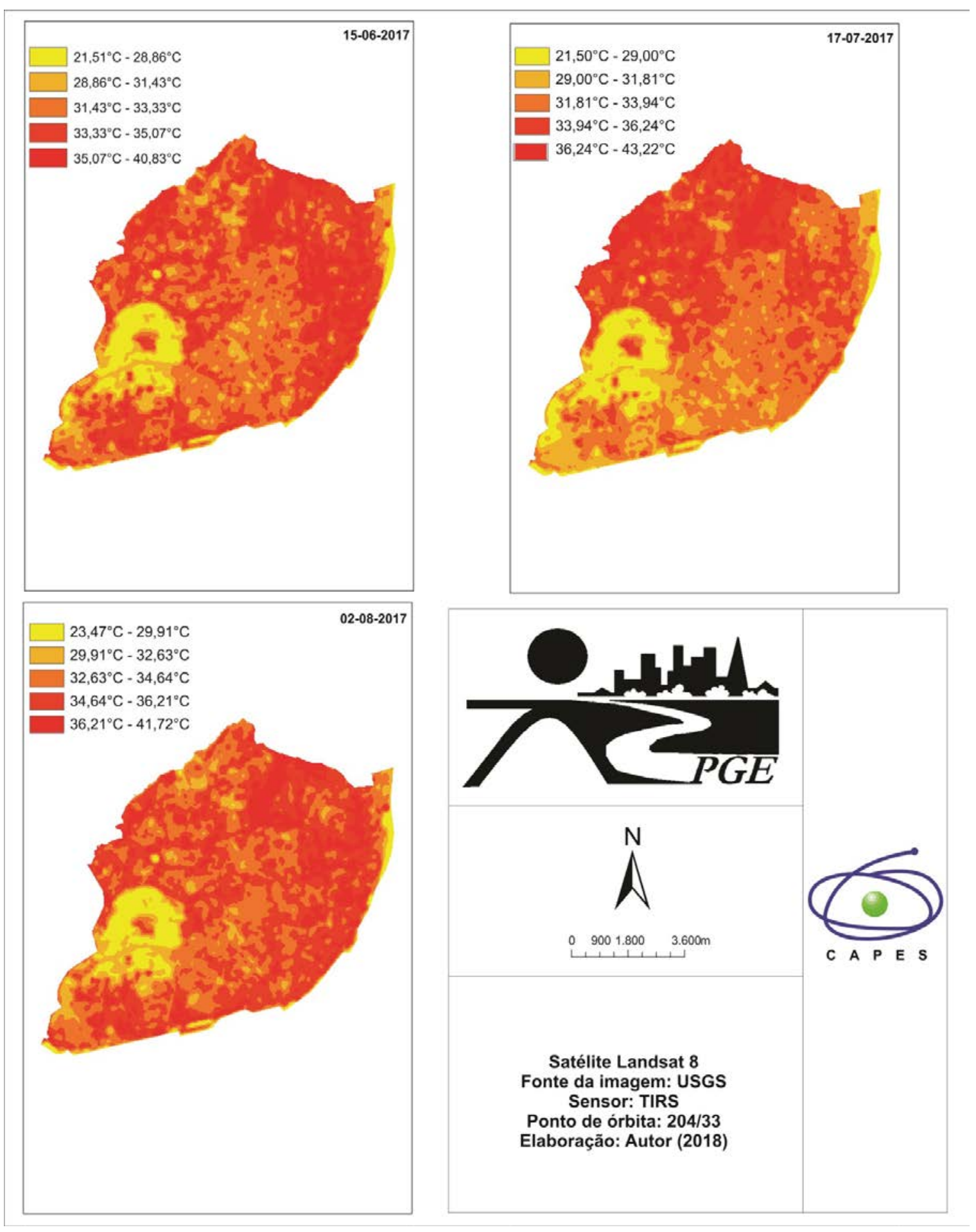

Figura 2. Mapa de TAS de Lisboa no verão de 2017.

As áreas verdes presentes na atualidade são em boa parte resultante dos lisboetas do século XIX, que no final do século referido, criaram inúmeras áreas verdes tais como: Jardim de $\mathrm{S}$.
Pedro de Alcântara (1864), Jardim do Príncipe Real (1859 e 1863), Campo de St $\underline{a}$. Clara (1862), Jardim da Praça das Flores, Miradouro do Alto de $\mathrm{St}^{\underline{a}}$. Catarina (1872), Jardim da Rocha Conde 
de Óbidos (1879), Campo de Santana, Praça da Alegria (Jardim Keil do Amaral), Parque Silva Porto e Jardim do novo bairro de Campo de Ourique (Almeida, 2006).

Mesmo com a gestão urbana promovendo investimentos desde o século XIX, as temperaturas de superfície são elevadas, devido à densa urbanização, materiais utilizados e sua morfologia.

Devido à importância do verde urbano estar na pauta da gestão urbana de Lisboa a séculos, na perspectiva sustentável, foi gerado o NDVI correspondente ao período analisedo na TAS, para tornar possível a correlação.

Em 15/06/2017, foi identificado que a menor classe entre as cinco originadas, possui valores entre $-0,166$ a 0,090 e, a maior 0,342 a 0,612. Os maiores valores concentraram-se a sudoeste, onde se localiza a maior concentração arbórea de elevada rugosidade. Em 17/07/2017 e em $02 / 08 / 2017$, os maiores valores e menores foram próximos ao mês de junho, em que os menores índices foram de $-0,093$ e -0,172, já os maiores 0,528 e 0,609 , respectivamente (Figura 3 ). Os pontos com os menores valores e maiores demonstraram-se espacialmente semelhantes ao se comparar as três imagens.

A localidade com os maiores valores de NDVI, está localizada na Freguesia de Benfica, por conta da presença do Parque Florestal Monsanto, em contra partida, à sudoeste de Lisboa, está a Freguesia de Santa Maria Mior, que obteve os menores valores do índice de vegetação. Mendes et al. (2015) por levantamento de imagem de satélite de alta resolução, também identificou que a freguesia de Benfica, é a que possui maior aglomeração arbórea, apresentando maior rugosidade pela copa das árvores, e a freguesia de Santa Maria Maior, a menor quantidade arbórea.

$\mathrm{Na}$ literatura consta identificação por muitos autores além de Mendes et al. (2015), que esta região possui a maior aglomeração verde (Massavanhane, 2010; Cardoso, 2011; Cabral et al., 2012), assim, corroborando com os valores de NDVI obtidos nesse estudo, todavia, estipulou-se os valores aproximados de vegetação.

Ao promover a comparação entre as temperaturas da TAS com os valores do NDVI, evidenciou-se que nas localidades com a maior rugosidade arbórea, no Parque florestal Monsanto, principalmente, são as lalidades que se obtém os maiores valores de NDVI e consequentemente os menores valores de TAS, assim, evidencia-se que o NDVI e a TAS, possuem relação inversamente proporcional.

Com alusão à relação inversamente proporcional entre NDVI e TAS, Lima e Amorim (2011) obtiveram resultado que corroboram com o obtido em Lisboa, de modo que, nas localidades que possuem menores valores de índice de vegetação, as temperaturas de superfícies são mais elevadas, e nas localidades com maiores valores de NDVI ocorrem as menores temperaturas de superfície, visto que, os Parques florestais, são fundamentais para o adensamento do verde urbano e, proporcionam discrepâncias nas temperaturas, em contrastes com a morfologia urbana.

Estes fatores interferem diretamente na formação e evolução do clima urbano, variando conforme suas características e densidades. Desse modo, comprova-se que a vegetação tem importante papel no meio urbano, principalmente no que concerne as condições agradáveis para a população, uma vez que a arborização é fundamental para mitigação das temperaturas. 


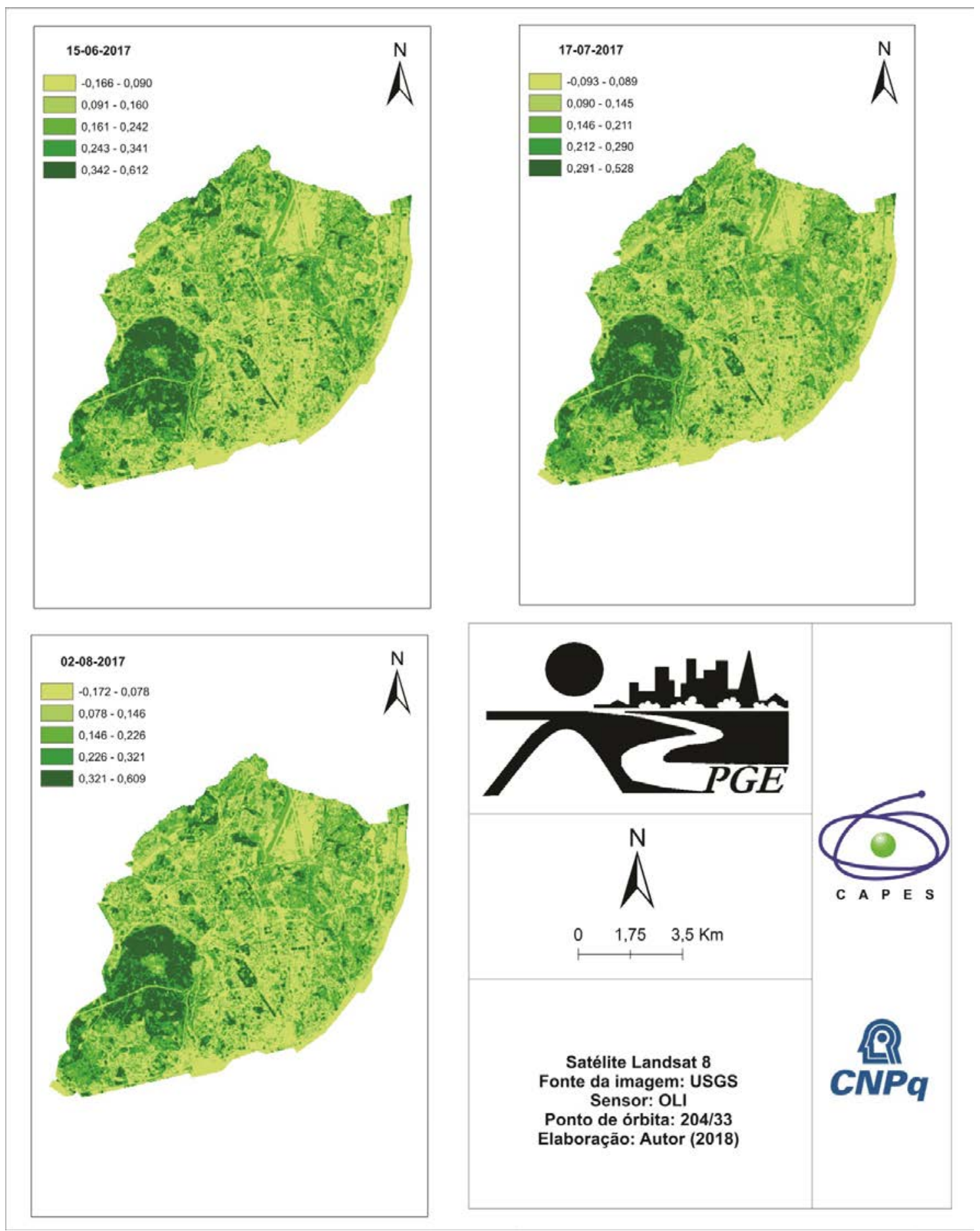

Figura 3. Mapa de NDVI de Lisboa no verão de 2017.

\section{Conclusão}

As informaçãoes originadas pelas imagens termais do satélite Landsat $8 \mathrm{da}$ banda 10, e para o NDVI, bandas 5 e 4, para averiguação do índice de vegetação, foram fundamentais para comprovação da influência da vegetação com elevado portencial para mitigação das temperaturas de superfícies na Cidade de Lisboa. 
Percebeu-se que o NDVI e a temperatura de superfície, são fundamentais para auxiliar na gestão do ambiente urbano, haja vista, que esses estudos apontam as localidades que necessitam primordialmente de atenção, no que concerna a ausência ou pouca vegetação correlacionada com as temperaturas de superfícies elevadas.

\section{Declaração de conflito de interesses}

Os autores declaram não haver conflito de interesses.

\section{Agradecimentos}

Os autores agradecem as Fundações CAPES e CNPq, pela bolsa de estudos concedida, que permitiu a realização deste estudo.

\section{Conflito de interesses}

Os autores declaram não haver conflito de interesses.

\section{Referências}

Almeida, A. L. B.S.S. S. L. 0 valor das árvores: árvores e floresta urbana de Lisboa. Lisboa: Universidade Técnica de Lisboa, 2006. (Tese de doutorado).

Amorim, M. C. C. T. Detecção remota de ilhas de calor superficiais: exemplos de cidades de porte médio e pequeno do ambiente tropical, Brasil. Finisterra - Revista Portuguesa de Geografia, v. 105, p.111-133, 2017. https://doi.org/10.18055/Finis6888

Amorim, M. C. C. T. Spatial variability and intensity frequency of surface heat island in a Brazilian city with continental tropical climate through remote sensing. Remote Sensing Applications: Society and Environment, $\quad$ v. 9, p. 10-16, 2018. https://doi.org/10.1016/j.rsase.2017.11.001

Cabral, M.; Pereira, H. M.; Cruz, C. S.; Mathias, M. L. $O$ Índice de Biodiversidade nas Cidades como ferramenta para gestão: o caso da cidade de Lisboa. Ecologi@, v. 6, p. 63-72, 2012. Disponível em: <https://www.speco. pt/images/Artigos_Revista_Ecologia/revistae cologia_6_art_8_1.pdf>. Acesso em: 05 jun. 2018.

Cardoso, M. C. Biodiversidade urbana: seleção e caracterização de indicadores para Lisboa. Lisboa: Universidade de Lisboa, 2011. (Dissertação de mestrado).

Costa, D. A.; Fridrich, G. A.; Marinho, R. S. A.; Pinheiro, M. P. G.; Miranda e Silva, J. C.; Santos, M. L. F.; Souza, A. H. F. F.; Crispim, M. C. Planejamento e gestão ambiental na Universidade Federal da Paraíba, Nordeste do Brasil: análise e contribuições. Revista Brasileira de Gestão Ambiental e Sustentabilidade, v. 4, n. 8, p. 233-254, 2017. https://doi.org/10.21438/rbgas. 040801

Deng, Y.; Wang, S.; Bai, X.; Tian, Y.; Wu, L.; Xiao, J.; Chen, F.; Qian, Q. Relationship among land surface temperature and LUCC, NDVI in typical karst area. Scientific Reports, v. 8, Article No.641, p. 1-12, 2018. https://doi.org/10.1038/s41598-01719088-x

Eduvirgem, R. V.; Ferreira, M. E. M. C. Temperatura aparente de superfície nos arredores do Córrego Moscados na Cidade de Maringá, Paraná. Revista Nacional de Gerenciamento de Cidades, v. 5, n. 34, p. 28-40, 2017. Disponível em: <http://www.amigosdanatureza.org.br/publ icacoes/index.php/gerenciamento_de_cidade s/article/view/1612/1599>. Acesso em: 05 jun. 2018.

Flores R., J. L.; Pereira Filho, A. J.; Karam, H. A. Estimation of long term low resolution surface urban heat island intensities for tropical cities using modis remote sensing data. Urban Climate, v. 17, p. 32-66, 2016. https://doi.org/10.1016/j.uclim.2016.04.002 Fu, B.; Burgher, I. Riparian vegetation NDVI dynamics and its relationship with climate, surface water and groundwater. Journal of Arid Environments, v. 113, p. 59-68, 2015. https://doi.org/10.1016/j.jaridenv.2014.09.0 10

INE - Instituto Nacional de Estatística. Censos 2011. Disponível em: <http://www.cmlisboa.pt/municipio/demografia>. Acesso em: 05 jun. 2018.

IPMA - Instituto Português do Mar e da Atmosfera. Verão 2017 extremamente seco. Disponível em: <https://www.ipma.pt/pt/ media/noticias/news.detail.jsp?f=/pt/media /noticias/arquivo/2017/verao-clima2017.html>. Acesso em: 12 fev. 2018. 
IPMA - Instituto Português do Mar e da Atmosfera. Área educativa - Clima de Portugal Continental. Disponível em: <http://www.ipma.pt/pt/educativa/tempo.c lima/index.jsp?page=clima.pt.xml>. Acesso em: 05 jun. 2018.

Lima, V.; Amorim, M. C. C. T. A utilização de informações de temperatura da superfície, do NDVI e de temperatura do ar na análise de qualidade ambiental urbana. Anais do XV Simpósio Brasileiro de Sensoriamento Remoto, Curitiba, p. 1028-1035. 2011. Disponível em: <http://marte.dpi.inpe.br/ col/dpi.inpe.br/marte/2011/07.14.19.00/do c/p1165.pdf>. Acesso em: 05 jun. 2018.

Lombardo, M. A. Ilhas de calor nas metrópoles: o exemplo de São Paulo. São Paulo: Hucitec. 1985.

Massavanhane, A. M. C. Avaliação do estado actual de desenvolvimento e da situação fitossanitária dos arvoredos, bosquetes e maciços classificados de interesse público do Concelho de Lisboa. Lisboa: Universidade Técnica de Lisboa, 2010. (Dissertação de mestrado).

Mendes, F. R.; Silva Filho, D. F.; Lopes, A. M. S. Proposta de metodologia para a quantificação da cobertura arbórea na Cidade de Lisboa a partir de imagem de alta resolução. Enciclopédia Biosfera, v. 11, n. 21, p. 3254-3265, 2015. Disponível em: <http://www.conhecer.org.br/enciclop/201 5b/multidisciplinar/Proposta $\% 20 \mathrm{de} \% 20$ met odologia.pdf>. Acesso em: 05 jun. 2018.

Monteiro, C. A. F. Teoria e clima urbano. São Paulo: Faculdade de Filosofia, Letras e Ciências Humanas, Universidade de São Paulo, 1976. (Tese livre docência).

Monteiro, C.A.F.; Mendonça, F. Clima urbano. São Paulo: Contexto, 2003.

Morais, L. I. R. Distribuição espacial da mortalidade em Lisboa associada às temperaturas elevadas, com recurso a sistemas de informação geográfica. Lisboa: Universidade de Lisboa, 2011. (Dissertação de mestrado).

Peng, S.; Piao, S.; Ciais, P.; Friedlingstein, P.; Ottle, C.; Bréon, F. M.; Nan, H.; Zhou, L.; Myneni, R. B. Surface urban heat island across 419 global big cities. Environmental Science \& Technology, v. 46, n. 2, p. 696703, 2011. https://doi.org/10.1021/ es2030438

Quesada, H. B.; Redondo, G.; Vernasqui, L. G.; Magnoni, P. H. J.; Arantes, E. J. Análise da vegetação ripária em bacia hidrográfica utilizando Índice de Vegetação Normalizada (NDVI) no Município de Maringá-PR. Geo UERJ, $\quad$ n. 31, p. 439-455, 2017. https://doi.org/10.12957/geouerj.2017.267 37

Silva, J. S.; Silva, R. M.; Santos, C. A. G. Spatiotemporal impact of land use/land cover changes on urban heat islands: A case study of Paço do Lumiar, Brazil. Building and Environment, v. 136, p. 279-292, 2018. https://doi.org/10.1016/j.buildenv.2018.03. 041

Whetton, R.; Zhao, Y.; Shaddad, S.; Mouazen, A. M. Nonlinear parametric modelling to study how soil properties affect crop yields and NDVI. Computers and Electronics in Agriculture, v. 138, p. 127-136, 2017. https://doi.org/10.1016/j.compag.2017.04.0 16

Zheng, Y.; Han, J.; Huang, Y.; Fassnacht, S. R.; Xie, S.; Lv, E.; Chen, M. Vegetation response to climate conditions based on NDVI simulations using stepwise cluster analysis for the Three-River Headwaters region of China. Ecological Indicators, v. 92, p. 18-29, 2018. https://doi.org/10.1016/j.ecolind. 2017.06.040 